\title{
Assessment of Traffic Safety Problems and Awareness of Road Users, the Case of Shashemene Town
}

\author{
Abdurahman Mohammed Kelacha \\ Civil Engineering Department, College of Engineering and Technology, Mettu University, Mettu, Ethiopia \\ Email address: \\ Abdu.moha430@gmail.com
}

\section{To cite this article:}

Abdurahman Mohammed Kelacha. Assessment of Traffic Safety Problems and Awareness of Road Users, the Case of Shashemene Town. International Journal of Transportation Engineering and Technology. Vol. 7, No. 2, 2021, pp. 33-47. doi: 10.11648/j.ijtet.20210702.11

Received: January 6, 2021; Accepted: January 16, 2021; Published: June 23, 2021

\begin{abstract}
Now days, road traffic accidents are one of the public health problems all over the worlds especially in developing countries like Ethiopia. This study was conducted using both descriptive and analytical methods. The sampling method used for this research was purposive sampling methods and the population represents this study was selected arbitrary. According to the finding of these research, the current road traffic safety problems of shashemene town are lack of awareness of pedestrians on traffic rule, lack of drivers skill, poor enforcement of law, insufficient speed breaker, width of road way, width of bridge, poor road side furniture, insufficient road safety consideration, drivers not respecting others road users, excessive speed, failure to give priority for pedestrians, risky overtaking, following each other's too closely and not respecting right hand rule are some of the variable that cause traffic accidents. Based on the vehicle type, the majority of accident is caused by dry freight vehicle (Isuzu, Sino and FSR) which covers $44 \%$, transport bus which covers $28 \%$, Minibus $14.5 \%$, motor cycle $7 \%$ taxi 3.6 and cart covers $3 \%$. the researcher also found that the major accident happen at study area is by human error (89\%) and the other are due to road problems, mechanical problems and environmental problems. According to vulnerability of road users to RTA, are categorized in to pedestrians $46.7 \%$, passengers $20.7 \%$, drivers $14.5 \%$, motorcyclist $6.9 \%$, cyclist and others covers $9.65 \%$. the researcher also identified black spot area and contributing factor of RTA at those areas. Accordingly the major traffic crashes are occurs on Kuyera road which covers $24 \%$, on kofele road $18 \%, 13 \%$ on Alaba road, exit of Awassa road $7 \%$ and also tekliye, kebele 010 around gomista 7\%, around Dadimos College $4 \%$ and in front of dr. urgessa clinic 7\% and zerihun garage covers 5\% from all the accident. Most of the traffic accident caused on this area is due to speed, not giving priority for pedestrians, lack of awareness on road traffic safety, due to poor law enforcement, due to driver's error (concerning skill and in attentiveness, driving after they take drug like chat and shisha) narrowness of the carriage way, absence of pedestrian's walkway and lack of road side furniture's.
\end{abstract}

Keywords: Assessment of Road Safety, Crash Severity, Road Traffic Accident and Road Users

\section{Introduction}

Road safety issues are one of the major economic, social and health problems, especially in the developing country like Ethiopia. According to the WHO report, an estimated of 1.25 million people are killed in road crashes and up to 50 million injured worldwide every year, on average 3,287 deaths a day [1]. Road traffic accident are becoming the leading cause of death among young people aged between 15 and 29 years, and cost governments approximately $3 \%$ of GDP (and up to 5\% In low- and middle-income countries). About $90 \%$ of the world's fatalities on the roads occur in low income and middle-income countries, which have only $54 \%$ of the world's registered vehicles [1].
It is known that Road traffic accidents are one of the most critical problems for human life. Despite widespread measures being used to control and minimize this problem, road traffic accidents are facing a growing trend, day to day. Addressing the preventable problem of inadequate road safety requires the dedicated action of multiple ministries, most notably law, planning, transport, education, public information, and health. The range of measures to ensure road safety includes improving the built environment (e.g., safer road design, regulating sidewalks and traffic lights, introducing safe bicycle lanes), law enforcement and education to increase seatbelt use and helmet wearing while reducing speeding and drink driving, better vehicle standards, and improved post-crash response. Road safety measures that provide safer, more sustainable 
public transport options are also particularly promising and can support synergies between health, transport and carbon emission reduction targets [2].

It is important to note that developed countries have succeeded in controlling traffic accidents. These attainments are the product of making infrastructure safer, improving the safety of vehicles and executing a number of other interventions recognized to be effective at reducing road traffic injuries. Having good quality data to monitor the impact of these efforts is also critical to signifying their accomplishment. However, developing and less-developed countries have not yet achieved this level of success. Regular road inspections are an important measure that helps to ensure the quality of roads and road surfaces. Considering some major factors (i.e., (1) institutional framework; (2) alcohol usage and speeds; (3) protective systems; (4) vehicles; (5) infrastructure and roads; and (6) trauma management, etc. [2].

It is obvious that the road traffic accident is high in developing countries. The African Region has the highest estimated road traffic death rates of 26.6 per 100,000 populations, relative to a global rate of 17.4. However, the region is the least motorized, with 46.6 vehicles per 1000 people - relative to 510.3 vehicles per 1000 people in the European region While the majority of countries in the region have enacted national laws on key behavioral risk factors (speed, drink-driving, motorcycle helmets, seat-belts and child restraints), in very few countries in the region do these laws meet best practice [3].

According to report of Understanding Passenger Influences On Driver Behaviour [3], Africa is over represented in terms of the number of road traffic deaths that occur on its roads, relative to its vehicle fleet: it contributes to $20 \%$ of the world's road traffic deaths but has only $2.3 \%$ of the world's vehicles. The African region has the highest proportion of pedestrianrelated deaths by $39 \%$. While the region has the lowest proportion of road traffic deaths among motorcyclists, at 7\%, this may be a result of poor data quality, because most of the participating countries were unable to provide detailed Data on deaths broken down by road user type [3].

The magnitude of traffic accidents are varies from place to place and highly takes place in Asian and sub Saharan countries; especially it is high on the pedestrians. As the study done on Pedestrian accidents and road safety education in selected developing countries shows our countries is the leading one by the traffic accident of pedestrians [4].

According to Addis Ababa Traffic Police Report (AATPR) About 3\% of the Ethiopian population met a traffic accident which is equivalent to about 3 million people who met traffic accident in 2015 [7]. Additionally, according to the report of [8], traffic accidents during the Ethiopian Fiscal Year 2016/17 that ended on July 8 , has led to the deaths of 4500 people which means about 4.5 million people are victim by traffic accident [4].

\section{Statement of the Problem}

The number of deaths on the world's roads remains unacceptably high, with an estimated 1.35 million people dying each year [5]. As who report of 2016 shows the rate of death relative to the size of the world's population has remained constant. When considered in the context of the increasing global population and rapid motorization that has taken place over the same period, this suggests that existing road safety efforts may have mitigated the situation from getting worse. However, it also indicates that progress to realize Sustainable Development Goal (SDG) target 3.6 which calls for a $50 \%$ reduction in the number of road traffic deaths by 2020 - remains far from sufficient [5].

According to many journal points of views, Traffic accidents are one of the major concerns worldwide; due to these were health and economic impacts on any society. Road crashes now days are becoming a global public health concern, especially in African countries. According to a World Health Organization report, Ethiopia is one of the 50 countries with the deadliest roads in the world [6].

The rate of road traffic death are high in Africa and SouthEast Asia which ranges 26.6 per 100,000 population of Africa and 20.7 deaths per 100,000 population of South-East Asia respectively. As reports of Assessment Of Road Traffic Crash Data Collection And Managment System [6], shows more than half of all road traffic deaths are among vulnerable road users: pedestrians, cyclists and motorcyclists. Africa has the highest proportion of pedestrian and cyclist mortalities with $44 \%$ of deaths. In South-East Asia and the Western Pacific, the majority of deaths are among riders of motorized two and three-wheelers, which represent $43 \%$ and $36 \%$ of all deaths respectively [7].

Each year, road traffic Crash causes a great loss of human and economic resources in Ethiopia. This problem is increasing from year to year at alarming rate accompanying the rapid increase of population and the number of vehicles [8].

In addition to the above mentioned problems that contribute to traffic accident, other problem that have seen at study area is; no conducted research in recent year to intervene the problems related to road traffic safety problems and awareness of road users in the town, no sufficient pedestrian walkway, Highly increasing number of motor vehicle, lack of traffic road signs, over speed, using phone cell while driving, Lack of awareness among road users on traffic safety rules and insufficient law enforcements are some of the problems seen at study areas.

Though, this study was under taken to assess traffic safety problems and awareness of road users in Shashemene town.

\section{Objectives of the Study}

\subsection{General Objectives}

The general objective of this study is to assess traffic safety problems and awareness of road users.

\subsection{Specific Objectives}

To characterize the current road traffic safety problems in Shashemene town.

To identify the major contributing factor of road traffic 
safety problems in the study area.

\section{Significance of Study}

This study was concerned with the Assessment of traffic safety problems and awareness of road users in Shashemene town. The major Consideration should be given for assessing, identifying black spot area, types of accident that repeatedly face road users, assessing road related problems and identifying major contributing factors of traffic crash, and effect of road user awareness on traffic safety.

Though, the significance of this study was used to identify the major contributing factor of traffic accidents and put its counter measures at study area and was used as benchmark to local and federal authorities for the future to determine the traffic safety problem and awareness of road users of the town easily and used as a reference to those who want to conduct future studies on assessment of road traffic safety problems, on awareness of road users and other related issues.

In general, this study is important to minimize the road safety problems in the study area and benefits Jimma Institute of Technology in accomplishing its objective as a center of academic excellence.

\section{Literature Review}

In this study, the researchers assessed several related literatures on assessment of road traffic safety problems, major causes and contributing factor of road traffic accident, effect of road cross sectional elements on traffic accident, possible countermeasure to reduce road accident and appropriate intervention can be recommended to minimize road traffic accident in Shashemene town. Therefore, the researcher provides the literature review of this study through scientific literature revision.

Road traffic accidents (RTAs) are huge public health and development problems. Every year nearly 1.3 million people lose their lives on the road and as many as 50 million others are injured. Globally 17 road fatalities per 100,000 populations per annum are reported. As According to many journals report, RTA is the second leading cause of death in economically active population group of 15-44 years of age and more than $75 \%$ of RTA casualties occur in this age group. In many countries the estimate economic loss due to RTAs is as high as $3 \%$ of their gross domestic products [9].

Road safety has become a global issue that ranks as one of the most pressing matters facing society today. The World Health Organization (WHO) Road Safety Status Report of 2015 defined the problem of road injuries as a major public health issue. Road fatalities and injuries were projected to be the third leading contributor to the global burden of disease and injury by 2020 [1].

According to the Magnitude Of Road Traffic Accident Related Injuries And Fatalities In Ethiopia of Tefari Abegazi [11], Road traffic crashes are now the leading cause of fatalities in developing countries for 15-19 year olds and the second among 5-14 year olds. Low and middle-income countries remain the most affected, because road traffic crashes and injuries are linked not only to the number of vehicles, road conditions and drivers' behavior and attitude towards road safety, but also to the country's level of economic and social development. The challenges faced by many countries are exacerbated by poor road infrastructure, vehicle types and features, ineffective traffic law enforcement, poor driving practices, corruption and delayed implementation of road safety policies amongst other factors [10].

Globally RTA fatalities remain more or less constant since 2007; yet, in many developing countries the rates are increasing. Especially Africa faces the highest annual rate of road fatalities in the world 27 per 100,000 populations In the next few decades, the problem can even soar due to the Ongoing rapid economic growth and increase in motorization in the continents [11].

\subsection{The Current Road Traffic Safety Problems and Its Characteristics in Ethiopia}

Road traffic safety refers to methods and measures for reducing the risk of a person using the road network being killed or seriously injured. Public agencies work to ensure that people arrive at their destination without incident. Road safety can be characterized by the ability of a person to travel freely without injury or death. A perfectly safe transportation system would not experience crashes between various road users. Though absence of all crashes is an optimal condition, and many transportation agencies have a goal of zero deaths on the road, the reality is that people continue to get injured or killed on streets and highways across the nation [12].

According to [12], research describe, the challenge posed to the road safety field is to minimize the frequency of crashes and the resulting deaths and injuries using all currently available tools, knowledge, and technology. Road safety professionals typically measure safety by the number and rate of crashes and by the severity of those crashes [12].

According to [12], Road traffic safety aims at reducing the harm (deaths, injuries, and property damage) on the highway systems from traffic collisions. It includes the design, construction and regulation of the roads, the vehicles that use them and also the training of drivers and other road-users. For the fulfillments of road traffic safety objectives, the responsible bodies develop, establish and implement systems [12].

The indicator of traffic safety problems is crash rate, crash frequency, crash severity, road characteristics and traffic volume. At the study area several road traffic safety problems are observed. Those problems are human related problems and road related problems. Human related problems are like not having good awareness on traffic rules, not respecting traffic regulation and using road side for their commercial purpose. The road related problems of the town were the design of road should not meet all its design standard criteria; like median, shoulder, traffic signal, not maintaining on time the defected part of the road and other road furniture [13].

Crash frequency: is the fundamental basis for safety analysis, selection of sites for treatment and evaluation of the effects of treatments and it is also used as a fundamental 
indicator of "safety" in the evaluation and estimation methods and is defined as the number of crashes occurring at a particular site, facility or network in a one-year period [13].

Crash frequency is calculated as follows

Crash frequency $=$ Number of crashes $\div$ Period in year

Crash Severity: is defined as the level of injury or property damage due to a crash.

Crash severity is often divided into categories according to the $\mathrm{KABCO}$ scale, which provides five levels of injury severity [14], the five KABCO crash severity levels are:

$\mathrm{K}$ - Fatal injury: an injury that results in death;

A - Incapacitating injury: any injury, other than a fatal injury, which prevents the injured person from walking, driving or normally continuing the activities the person was capable of performing before the injury occurred;

B - Non-incapacitating evident injury: any injury, other than a fatal injury or an incapacitating injury, which is evident to observers at the scene of the accident in which the injury occurred;

C - Possible injury: any injury reported or claimed which is not a fatal injury, incapacitating injury or nonincapacitating evident injury and includes claim of injuries not evident;

O - No Injury/Property Damage Only (PDO) [14].

On this case study the crash severity obtained from Shashemene police commission are divided into fatal injuries, Incapacitating injury (major injuries), Simple injuries and Property damage only.

\subsection{The Current Road Network and Its Characteristics}

Road characteristics data is referred to as road inventory data. The most basic road characteristics data typically includes road name or route number, road classification, location coordinates, number of lanes, lane width, shoulder width, and median type [15].

Ethiopia has shown a considerable progress in road sector development in recent years through the construction of many roads. The Road Sector Development Program (RSDP) of the country has put as a strategy which can take the major share for this progress. This has brought a significant improvement in the country road network [15].

The following tables shows the current road network of Ethiopia and its growth rate with their classification

Table 1. The current Ethiopian road network and growth rate [15].

\begin{tabular}{|c|c|c|c|c|c|c|c|}
\hline \multirow{2}{*}{ Year } & \multicolumn{4}{|c|}{ Road networks in KM } & & \multirow{2}{*}{$\begin{array}{l}\text { Road density } \\
\text { per } 1000\end{array}$} & \multirow{2}{*}{$\begin{array}{l}\text { Road density per } \\
1000 \text { S.q km }\end{array}$} \\
\hline & Asphalt & gravel & Rural & Total & & & \\
\hline 2005 & 4,972 & 13,640 & 18,406 & 37,018 & 1.4 & 0.51 & 33.6 \\
\hline 2006 & 5,002 & 14,311 & 20,164 & 39,477 & 6.6 & 0.53 & 35.89 \\
\hline 2007 & 5,452 & 14,628 & 22,349 & 42,429 & 75 & 0.55 & 38.6 \\
\hline 2008 & 6,066 & 14,363 & 23,930 & 44,359 & 4.5 & 0.56 & 40.3 \\
\hline 2009 & 6,938 & 14,234 & 25,640 & 46,812 & 5.5 & 0.57 & 42.6 \\
\hline 2010 & 7,476 & 14,373 & 26,944 & 48,793 & 4.2 & 0.58 & 44.39 \\
\hline 2012 & 9,875 & 14,675 & 31,550 & 63,083 & 16.8 & 0.75 & 57.3 \\
\hline 2013 & 11,301 & 14,455 & 32,582 & 85,966 & 36.3 & 1.00 & 78.2 \\
\hline 2014 & 12,640 & 14,217 & 33,609 & 99,552 & 15.8 & 1.10 & 90.5 \\
\hline
\end{tabular}

Source: Ethiopia road authority Shashemene district 2015.

From the table above we can understand that in the last ten years the total road network of the country has significantly increased from $37,018 \mathrm{~km}$ with a road density of 0.51 per thousand people and 33.6 per thousand square $\mathrm{km}$ in the year 2005 to $99,522 \mathrm{~km}$ with a road density of $1.1 \mathrm{~km}$ per thousand people and $90.5 \mathrm{~km}$ per thousand square $\mathrm{km}$ in the year 2014. The average annual growth rate is about $9.0 \%$.

Moreover, the URRAP program, which started in the year 2011, has contributed a lot for increase of road network in the country; though its functionality needs further research.

The country has also been showing a considerable increase in traffic volume as a result of the economic development registered with an average annual GDP growth of $6.5 \%$ for the past ten years

From the total road network coverage of the country Shashemene town also shares some percent from total of the country. Those classification of road of Shashemene town are asphalt concrete $1063 \mathrm{~km}$, surface dressing $103 \mathrm{~km}$, gravel 2011 and rural road and additionally cobble stone $3 \mathrm{~km}$ are constructed in the town which are used as feeder roads. These means the coverage of road in Shashemene town are $3.2 \%$ of the country road which is small when compare to the town population and width.

Table 2. Current Shashemene town road network segment information.

\begin{tabular}{lllllll}
\hline $\begin{array}{l}\text { Road } \\
\text { Segment }\end{array}$ & Length & Road ID & Traffic condition & $\begin{array}{l}\text { Surface } \\
\text { type }\end{array}$ & DS standard & Road classification \\
\hline Shash-Batu & 90 & A7-2 & Heavy and middle & Paved & DS-3 & Trunk \\
Shash-Awassa & 25 & A8-1 & Heavy and middle & Paved & DS-3 & Trunk \\
Shash-Alaba & 64 & A7-3 & Heavy and middle & Paved & DS-4 & Trunk \\
Shash-Kofele & 26 & B81 & Heavy and middle & Paved & DS-3 & Trunk \\
Shash -w/Genet & 13 & A8a & Heavy and middle & Paved & DS-4 & Trunk \\
\hline
\end{tabular}

Source: ERA Shashemene district 2019. 
The total length of Shashemene road networks covers 3,180KM. From these Asphalt pavements 1063, surface dressing 103, cobble stone 3 and gravel road of $2011 \mathrm{~km}$ respectively. These shows as the town still have minimum coverage of asphalt and surface dress roads and also the road network are not enough for the road users. The above figures in percentage are as follows.

Gravel road $63 \%$, asphalt $34 \%$ and surface dressing covers $3 \%$.

\subsection{Identifying Black Spot Area}

According to several journals conclusion, the main objectives of black spot are:

To identify locations for further study which have both a high risk of crash losses and an economically justifiable opportunity for reducing the risk identify countermeasure options and priorities which maximize the economic benefits [16].

According to this report, highway accident black spots are road locations where the potential for accidents are unacceptably high or highest number or rate of accident happening in a certain location.

There are different methods which are applied in different countries and by different researchers for the identifications of road accident black spots. And there are also different manuals prepared which guides for the identification of road traffic accident black spots [17], But the problem or limitation is the manuals are prepared based on the standards of the countries and defines their own criteria's for the locations of the accident spots [17].

One of the method used in this research for the identification of road traffic accident black spot is a statistical method called Rate Quality Control method. This method consists of computing three different parameters for each road sections [17].

The three parameters includes accident rate, accident frequency and severity index and the logic of this method is a location or section of the road is road traffic accident black spot if the parameter gives high values than the other similar sites [17].

On the other hand the accident black spot can be identified by using a conventional method.

In which it relies on fixed length of road sections, where the total length is divided into 300,500 and $1000 \mathrm{~m}$ road sections. Based on fixed length of road sections divided the Number of accident happened with in each road section is calculated and compared to the Black spot criteria defined [18].

In different countries there are different criteria's for the analysis and identification of black spots areas. For instance in Australia at least 3 causality crushes in 5 years, In England with in $300 \mathrm{~m}$ road section 12 crashes in 3 years, in Germany with the same road section in England 8 crashes in 3 years, in Norway with in $100 \mathrm{~m}$ road section 4 crashes in 3 years and in Thailand with varying road section length at least 3 crashes in 1 year defines the sections as road traffic accident hazardous locations [19].

Besides this some of them use priority value for the identification of hazardous locations.

According to this method in order to be the location is road black spot area it must exceed.

Some value [17]. In Belgium, each site where in the last three years three or more accidents have occurred is selected. Then, a site is considered to be dangerous when its priority value $(\mathrm{P})$, calculated using the following formula, equals 15 or more

$$
\mathrm{P}=\mathrm{X}+3 \mathrm{Y}+5 \mathrm{Z}
$$

Where, $\mathrm{P}=$ priority value

$\mathrm{X}=$ total number of light injuries

$\mathrm{Y}=$ total number of serious injuries

$\mathrm{Z}=$ total number of death. This could be the simplest and clear method to rank a given location and can be used if the three parameters are available [17].

In Ethiopia there are also researches conducted related to the identification of road traffic

Accident black spots, one of these researches had been conducted in Addis Ababa-Shashemene road for the identification of road traffic accident black spots with their causes and proposing low cost engineering measures [18].

In addition to the above mentioned, the researcher uses several methods. From those method using previous information of the site which is obtained from police and population of the area by making inspection during data collection, preparing questionnaires' and interview, using manuals and guideline of standard of countries, based on AADT of the segment and its length, and based on traffic accident recorded data obtained from the police commission of the town.

\subsection{Contributing Factor of Traffic Accidents}

As evidences shows from other studies confirm, majority of the RTAs in the developing world affect all communities, but the extent to which they affect populations in Ethiopia is over whelming. As road traffic accidents pose a huge development and health problem, government need to take action to address road safety in a holistic manner, that requires involvement from multiple sectors (transport, police, health, education) and that addresses the safety of roads, vehicles, and road users [11].

To curb the growing problem, high level political commitment and immediate actions and decisions are required in the current situation Thus; all dwellers should be trained to be good road users at all stages of their lives [17], the training and education system should also start at home among family members. A strong commitment is needed towards road safety education in schools. According to traffic police reports, almost all errors were attributed to drivers. To this effect, there should be viable means in due course of improving the standards of driving. Moreover, maintenance of the road, traffic light, signs and symbols and strengthening and implementation of vehicletesting procedure are urgently needed [19].

It is obvious that the major cause of traffic accident is due human error, vehicle condition, road and environmental 
factors and it is also caused due to highly increasing number of vehicle and due to construction and urbanization.

To identify specifically and give the degree of their error let us see the other literatures. According to research of Alemu 2015, six main categories contributing to accidents are drive related, pedestrian related, vehicle related, road related, environmental related causes and other causes. Most of highly contributing causes provided to be driver related. These included loss of control of driving wheel, over speed, sudden slowing/ stoppage. Vehicle related causes were tire burst and vehicle turn over or vehicle turn off the road. Together, these six causes contributed around $83 \%$ of all accident causes on the five roads. Driver related causes contributed around $59-73 \%$ followed by vehicle related causes contributing in the range of $23 \%$. Pedestrian related causes also contributed around $4 \%$ while road related causes are also in the range of $3.5 \%$ [8].

The evidences in low income countries in sub-Saharan Africa region including Ethiopia the mortality and morbidity due to road traffic crashes is higher and even expected to become more worse in the future due to increasing number of vehicles and national development according to WHO report in 2009 and the factors contributing to these crashes are classified in to three; one is human factor (reckless driving, excessive speeding, over taking errors, alcohol use negligent, Pedestrians, passengers, cyclists and cart pushers). the second factor is external factor (poor road conditions, bad surface, and lack of road signs and marking and the third one is vehicle condition (poor mechanical condition like nondurable tires, poor body work, defective breaks and lose wheel nuts) [8].

According to Fundamentals of Roadway Safety; road traffic crashes have the following three general categories of contributing factors:

Human factors: including age, judgment, driver skill, inattention, fatigue, experience, using cell phone, and failure to wear seat belts.

Vehicle: including brake failure, tire blowout, design, manufacture and maintenance;

Roadway/Environment: including geometric alignment, cross section, traffic control devises, surface friction, grade, weather and visibility.

According to his research, Environmental/road user factors account for $48.8 \%$ followed by environmental/ vehicle road user factors $(16.4 \%)$, road user factors $(12.4 \%)$, vehicle/ road user factors $(7.2 \%)$, environmental factors $(5.6 \%)$ and environmental/vehicle factors (4.8\%). And in a wider ranging on-the spot study by TRL, human factors are the sole reason in $65 \%$ of the cases and a contributory cause in $95 \%$. About $25 \%$ of the crashes studied displayed a deficiency in the road, environment linked to a driver error [17].

Having in mind the above mentioned information the researcher made observation, interview and prepare questionnaires to identify the contributing factor of traffic accidents at study areas. Accordingly, the major contributing factor of traffic accident happen at study area are due to carelessness and lack of skill of drivers and road related problems like width of road and lack of road medians and also awareness of pedestrians on road traffic safety rules are the major cause of traffic accident at study areas.

\section{Methodology}

\subsection{Description of Study Area}

This study was conducted in Oromia regional state WestArsi zone Shashemene town which was located in central part of Ethiopia. The town is located $250 \mathrm{~km}$ far from capital of the country Addis Ababa city. Shashemene town is the oldest and now the capital of west Arsi zone. The town was densely populated and have estimated population of 383,938 in 2012 E.C. the town have land area of 12,930.6 hectares with truck five major ethnic groups. From these Oromo 67\%, Amhara 9.3\%, Wolayta 5\%, sodo Gurage 2\%, Kambata 2\% and other groups of $5.7 \%$. The town was divided into eight (8) kebele administration [15].

\subsection{Study population}

The total population considered in this research was those that give full information for researcher. They are pedestrians, drivers, passenger and other stakeholders like traffic police, transport authority and ERA stakeholders.

\subsection{Sample Size and Sampling Technique}

\subsubsection{Sample Size}

The sampling method used for this research was purposive and random sampling methods. The population represents the study was selected arbitrary as it was used to produce well organized groups of samples. The sample was picked according to their importance from each mentioned black spot area for the study. This enables the researcher to select participants from each road users and stake holders. The samples taken for the study are pedestrians 60 , drivers 50 , and stake holders and traffic police 10 and Total of 120 samples was selected.

\subsubsection{Sampling Technique}

To meet the objective of these study questionnaires survey was designed and distributed for those selected as a sample on the study area to identify the road user's awareness. In addition to these to identify whether the road users violate traffic rules or not the researcher use observational survey and interview with drivers, pedestrians and stake holders.

\subsection{Study Variables}

The variables used for this study are both dependent variables and independent variables.

\subsubsection{Dependent Variables}

Road traffic safety problems.

\subsubsection{Independent Variables}

The followings are some of the independent variables for this study. 
Inadequate pedestrian's walkway.

Identified black spot areas.

Frequency of crashes.

\subsection{Data Collection Procedures}

Before data collection the researcher describes the aim of the research and what is going to be done from the site and type of data to be collected. Then go to the site with traffic police to identify the site. These where based on previous road user's crash data, traffic volume and based on community information. Finally, both primary and secondary data was collected for the study.

\subsubsection{Primary Data}

Primary data collected in this study was by making site observation, making interview with different road users and stake holders, and through questionnaires which is used for road safety audit.

When conducting road safety audit, the identified problems of road design and road side furniture are: width of shoulder and carriage way was checked, provision of median barriers was checked, provision of speed limit, traffic sign was checked, adequacy of carriage way and width of bridge was checked.

\subsubsection{Secondary Data}

The secondary data needs for this study was collected through literature review, recorded document of traffic police on traffic accident data, from ERA and district transport office.

\subsection{Data Processing and Analysis}

Both primary and secondary collected data are analyzed by using statistical analysis. The quantitative data are used to explain the general characteristics of road traffic accident at study location. In these studies it is used to know the types of traffic accident which was high when compared to others severity and also to examine the relationship between the severity and contributing factors.

To figure out the rest assessment of traffic safety problems the collected data was analyzed by Microsoft excel. In this the collected severity data was categorized into fatal injury, major injury, minor injury and property damage.

Chart, table and graphical representation were used to visualize the variability and properties of data. Depending on the analysis, conclusion and recommendation was forwarded.

\section{Results and Discussion}

\subsection{General about Discussion}

In these research the assessment of road safety problems of study area, factor that contribute to the traffic accident, awareness of road users, type of accident that occurred at study area and different variables that related to the traffic accident was discussed in details.

\subsubsection{Road Traffic Accident Distribution During (2014- 2018)}

The major contributing factors for the cause of RTA at the study areas are: over speed, pedestrian's errors, not giving priority for pedestrians and not respecting other road users, insufficient skill of drivers, failure to respect right hand rule and road conditions were some of the factors that cause traffic accidents. According to the police reports more than $75 \%$ of traffic accident is caused due to driver's problems, pedestrian's error $9 \%$ and road factors and $7 \%$ respectively. Based on the above and collected data, the road user groups which require awareness on traffic rules and regulation highly are drivers, school children, elders and other road users respectively.

The traffic accidents of last past five years (2014 -2018) recorded by traffic police of the town are shown in the Figure 1.

As described in the Figure 1, the maximum number of injuries are recorded in 2014 which accounts $30.32 \%, 2015$ (21.8\%), 2018 (18.6\%), 2017 (16.49\%) and 2016 (13.8\%) of total injuries are recorded. These values cannot include the property damage happen during this period.

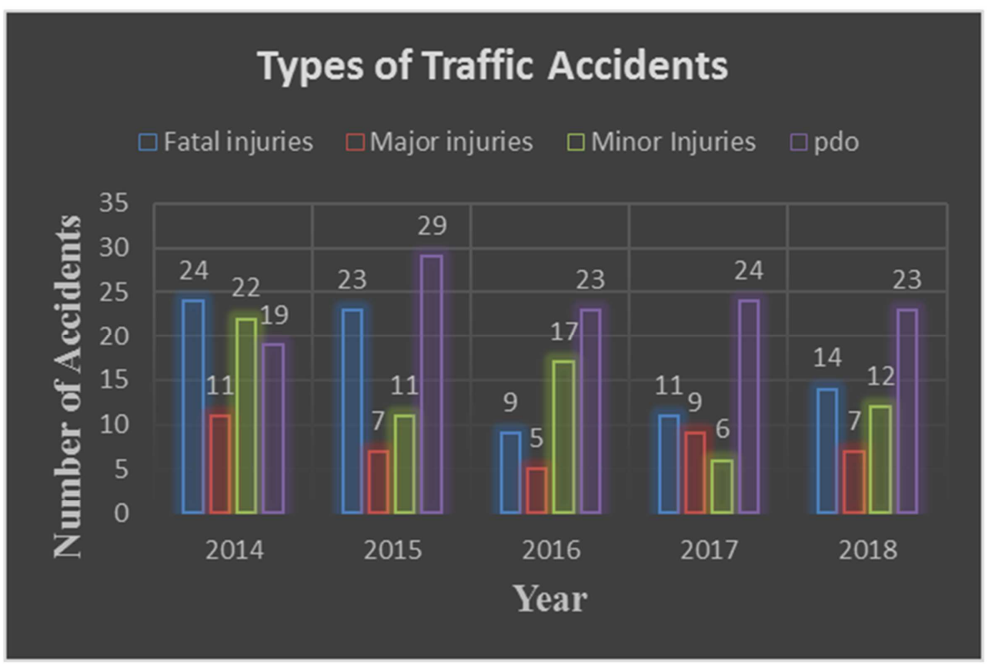

Figure 1. Distribution of traffic accident in Shashemene town (2014-2018). 
As seen from the above Figure, total injuries occurred at the study area during (2014 -2018), was 188. From these fatal injuries covers $43 \%$, major injuries $20.74 \%$ and minor injuries $36.17 \%$.

\subsubsection{Road Traffic Accident Distribution on Property Damage}

Generally, in the past five year (2014-2018), Shashemene town loses about 4,568,958 birr. The distribution of property damage and its cost are described in the table 3 below.

As seen from the table 3 , the maximum property damage is caused in 2015 which accounts $35.15 \%$ of total cost in birr from all property damage occurred in five years. The minimum property damage is recorded in 2017 which covers $8.46 \%$ of total property damage cost.

Table 3. Distribution of traffic accident and property damage.

\begin{tabular}{llll}
\hline Year & Property damage & Cost in birr & Percent \\
\hline 2014 & 19 & $1,263,250$ & $27.65 \%$ \\
2015 & 29 & $1,605,500$ & $35.13 \%$ \\
2016 & 23 & 658,428 & $14.42 \%$ \\
2017 & 22 & 386,500 & $8.46 \%$ \\
2018 & 23 & 655,280 & $14.34 \%$ \\
Total & 116 & $4,568,958.00$ & $100 \%$ \\
\hline
\end{tabular}

Source: compiled from Shashemene traffic police commission 2019
Based on the table 3, the town loses maximum amount of money in the year of 2014 and 2015 and lowest money in 2017 which covers total of $62.78 \%$ of the money that the town lost during $2014-2018$.

\subsubsection{Crash Rate}

Crash rate is obtained by multiplying number of accident occurred at that location by $100,000,000$ and dividing by 365 , length of the route in miles, AADT of the route and periods of recorded data.

According to this research, the highest crash rate is happen at road segment of Shashemene to Kofele road which accounts 85.5 per $100,000,000$ million peoples and Shashemene to $\mathrm{W} /$ Genet 67.8, Shashemene to Awassa 27.9, Shashemene to Alaba road 15.4 and Shashemene to Batu 15.1. As seen from the table 3 , Average crash rate of traffic accident per $100,000,000$ vehicles was 42.35 peoples.

Since the crash rate is one the indicators of traffic safety problems, the existence of this crash rate shows traffic safety problems at study areas which have no big difference when compared to the country crash rate which is 25.3 per 100 , 000 population.

Table 4. Distribution of observed traffic crashes per unit of traffic volume.

\begin{tabular}{|c|c|c|c|c|}
\hline Location & Total RTAs & Length of road (miles) & AADT & Crash rate \\
\hline Shash-Batu & 74 & 56.25 & 4774 & 15.1 \\
\hline Shash-Kofele & 54 & 16.25 & 2129 & 85.5 \\
\hline Shash-W. Genet & 19 & 8.125 & 1890 & 67.8 \\
\hline Shash- Awassa & 23 & 15.625 & 2890 & 27.9 \\
\hline Shash-Alaba & 40 & 40 & 3549 & 15.4 \\
\hline
\end{tabular}

The period of data used for the calculation or crash rate is five year which is from $2014-2018$. Therefore it has to keep in mind while calculating crash rate.

\subsubsection{Crash Frequency}

The Figure 2 shows the crash severity that are occurred during $2014-2018$

As seen in the literature reviews the number of crash frequency is obtained by dividing crashes happen by number of period in the year which is 5 year

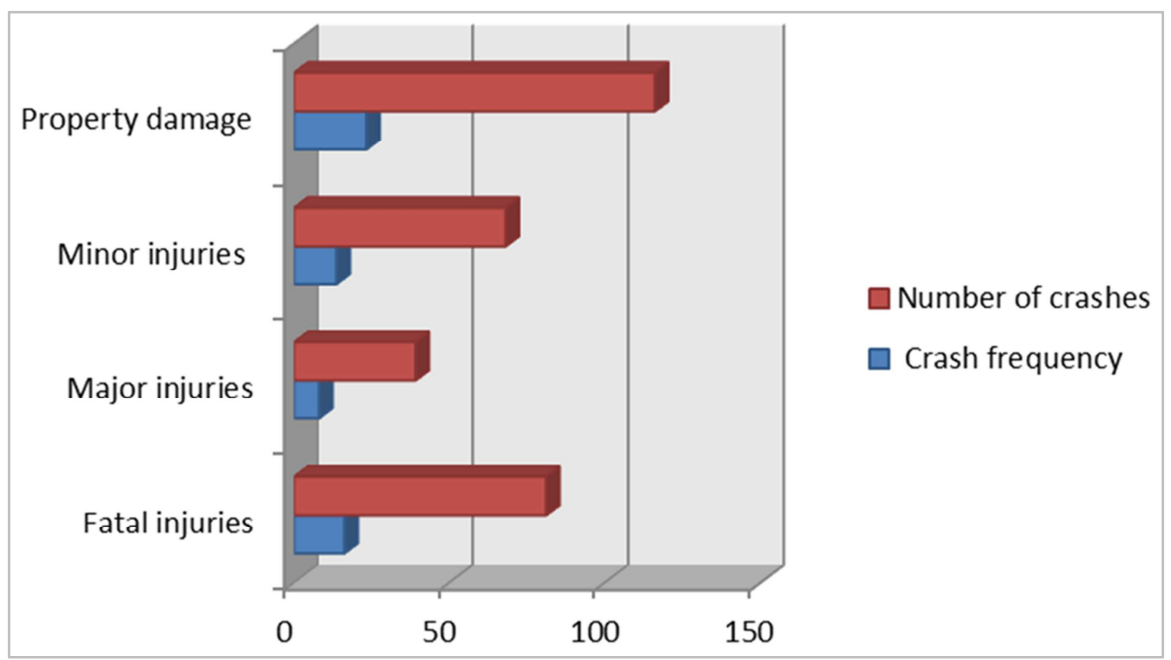

Figure 2. Crash Frequency. 
As seen from the Figure 2, above crash frequency is high for property damage which is 23.2 , fatal injuries are 16.2, minor injuries accounts 13.6 and major injuries are 8 which are the lowest from all crash at the study areas.

\subsubsection{Crash Severity at Shashemene Town (2014 - 2018)}

As observed from the figure 3 , the maximum number of accident is recorded in 2014 and 2015 respectively and lowest values of accident are happening in 2017. From total of the crash severity, major injuries accounts $12.8 \%$, minor injuries covers $21.7 \%$, fatal injuries $26.6 \%$ and property damage covers $38.9 \%$.

This indicates the problems of traffic safety problems are causing high numbers of fatal injuries next to property damage in the study areas.

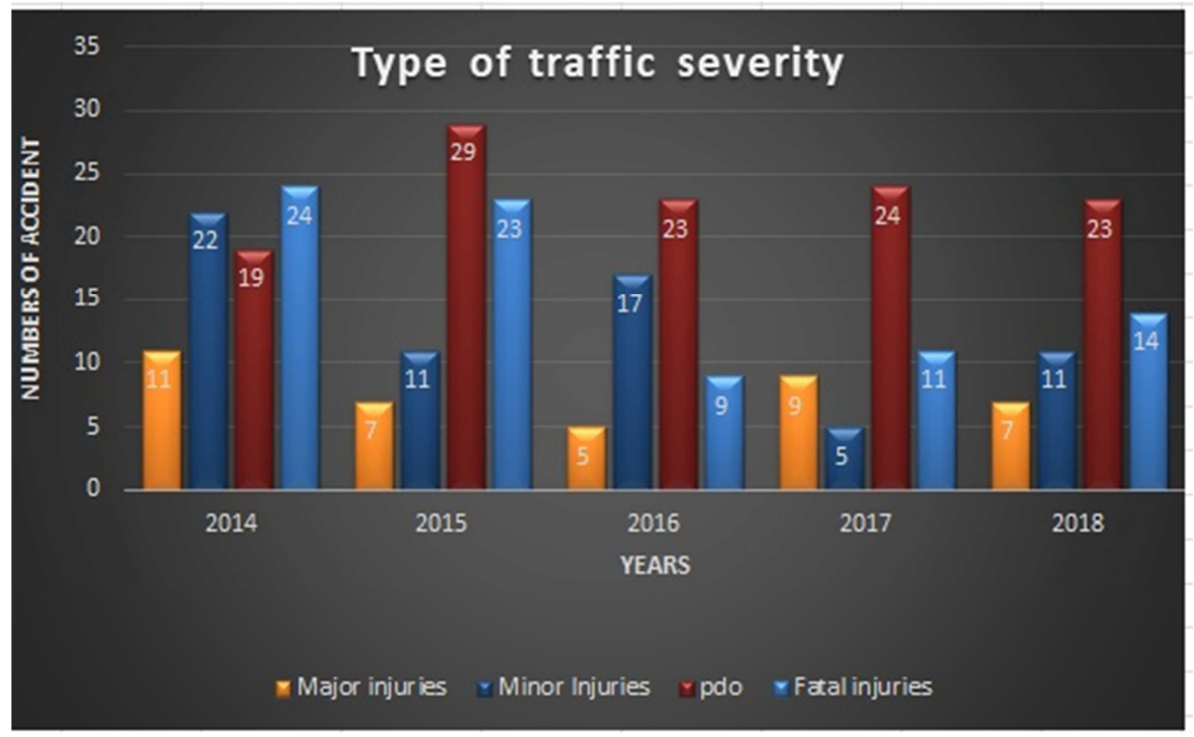

Figure 3. Crash Severities by type during 2014-2018.

\subsubsection{Vehicle Type and Distribution of Road Traffic Accident}

According to report of the traffic police and transportation institution of the town, means of transportation can be categorized in to cart, motorcycle, Bajaj, small van and utility, taxi, minibus, bus truck which carry from 24-120 quintals (Isuzu and FSR) and heavy truck.

Accordingly, the frequency distributions of traffic characteristics involved on accidents at the study area during (2014-2018) are recorded in Figure 4, below. In addition to this there are a lot of accident injuries which is not recorded and a lot of vehicle which is not under the rules. But cause accident and violate the traffic rules.

Base on the vehicle type that are involved in the accident during (2014 -2018) at the study areas, the majority of accident is caused by dry freight vehicle (Isuzu, Sino and FSR) $44 \%$, transport bus which covers $28 \%$, Minibus $14.5 \%$, motor cycle $7 \%$ taxi 3.6 and cart covers $3 \%$.

The reason of these is dry freight vehicle causes high accident is that due to speed, moves at night after they use drug, chew chat and due to distractive drivers (like using cell phone and talking with other). The next one is transport buses which go long distance, due to this they become tired and drive in attentively. Due to their fatigue and multi road user available on the road they try to overtake and not give priority for other road users to arrive their destination. Such type of behavior means inappropriate overtake and driving inattentively are the main incidence of traffic accident seen at study areas.

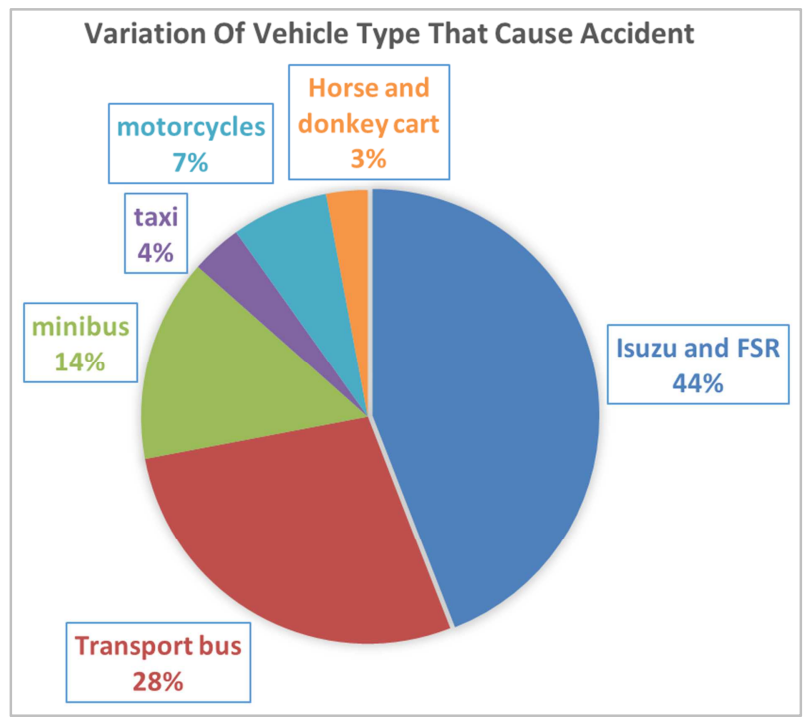

Figure 4. Vehicle type and traffic accident.

\subsection{Contributing Factors of Traffic Safety Problems}

To identify a major factor that causes traffic accidents, the researcher made site observation, made interview with some stake holders and road users and use prepared questionnaires' and uses safety audit check list. According to information obtained from site observation, interview and questionnaires the researcher try to categorize into pedestrians related 
problems, drivers related problems, road related problems and vehicle related problems

\subsubsection{Based on Questionnaire and Interview Factors That Causes Road Traffic Accidents}

The researcher prepared the questionnaires to get full information about the awareness of road users, road traffic safety problems that cause the traffic accident, traffic type, road accident type and to identify the one which is highly affected by the traffic accidents.

Table 5. Sample Size of Respondent for Questionnaires.

\begin{tabular}{lllllllll}
\hline \multirow{2}{*}{ Location } & \multicolumn{2}{l}{ Sample size for questionnaires } & \multicolumn{5}{l}{ Sample size for interview } \\
\cline { 2 - 8 } & pedestrian & drivers & police & Stake holder & pedestrian & drivers & police & Stake holders \\
\hline Kuyera road & 10 & 10 & 1 & 0 & 5 & 3 & 1 & 1 \\
Kofele road & 10 & 10 & 1 & 1 & 5 & 3 & 1 & 0 \\
010 (gomista) & 5 & 2 & 1 & 0 & 1 & 1 & 0 & 0 \\
Around Dadimos college & 3 & 1 & 1 & 0 & 2 & 1 & 0 & 0 \\
Awassa exit (tele) & 5 & 5 & 1 & 0 & 2 & 3 & 0 & 0 \\
Alaba exit & 5 & 5 & 1 & 0 & 3 & 3 & 0 & 0 \\
Tekliye & 2 & 2 & 0 & 0 & 2 & 1 & 0 & 0 \\
\hline
\end{tabular}

The questionnaires are prepared by classifying the road users as, pedestrian, drivers and stake holders.

Totally 120 questionnaires are prepared and distributed to the sample of selected respondents. From these, 78 questionnaires are fully completed and 42 questionnaires are partially filled. But all the questionnaires are returned even if the full information is not obtained.

In addition to this to identify effects of road cross sectional elements on RTA, field observational survey was made on selected area and compared with ERA standard and check list.

\subsubsection{Traffic Safety Problems Obtained from Pedestrians Perspective's}

To identify the factor that causes road traffic safety problems, the researcher uses several methods. From those method; using questionnaires, interviews and observational survey.

To know the awareness of pedestrians on road traffic safety regulations, the samples are selected randomly from all identified back spot area. The total number of pedestrian's respondent participated on this research is 60 .

\section{(i). Demography of Respondents}

Table 6. Demography of pedestrian respondents.

\begin{tabular}{llll}
\hline background & Number of respondent & & Percent\% \\
\hline \multirow{4}{*}{ Age } & $<15$ & 9 & 15 \\
& $16-29$ & 30 & 50 \\
\multirow{4}{*}{ Gender } & $30-49$ & 18 & 30 \\
& $>50$ & 3 & 5 \\
\multirow{3}{*}{ Educational level } & Male & 51 & 85 \\
& Female & 9 & 15 \\
& Illiterate & 5 & 8.33 \\
& Primary school & 29 & 48.33 \\
& Complete grade 10 & 19 & 31.67 \\
& Attend college/university & 7 & 11.67 \\
\hline
\end{tabular}

From these $51(85 \%)$ are male and $9(15 \%)$ are females.

There educational level is categorized as $8.3 \%$ of the respondent is illiterate, $48.3 \%$ follows primary school, $31.67 \%$ completes grade ten and $11.67 \%$ attend college education.

According to assessment made on age of the respondents classified as $15 \%$ are less than 15 years, $50 \%$ of the respondents are between $16-29$ years, $30 \%$ of respondents are between $30-49$ years and $5 \%$ of respondents are greater than 50 years old.

When assessing the awareness of respondents regarding traffic rules and road side furniture, are (41) $68.33 \%$ are aware of traffic rules and (19) $31.67 \%$ of the respondents are not aware.

Based on the assessment made on the participant's awareness of how they use zebra sign, from 60 respondents $49(81.67 \%)$ are aware and $11(18.33 \%)$ of respondent are not know the use of zebra and not use zebra. The other question prepared for pedestrians are whether they know/ not know the correct side of their movement while using the roads. On this 45 (75\%) of the respondents are aware and 15 $(25 \%)$ of the respondent are not aware at all.

Accordingly the information obtained from pedestrians' perspectives on the road traffic safety problems is listed.

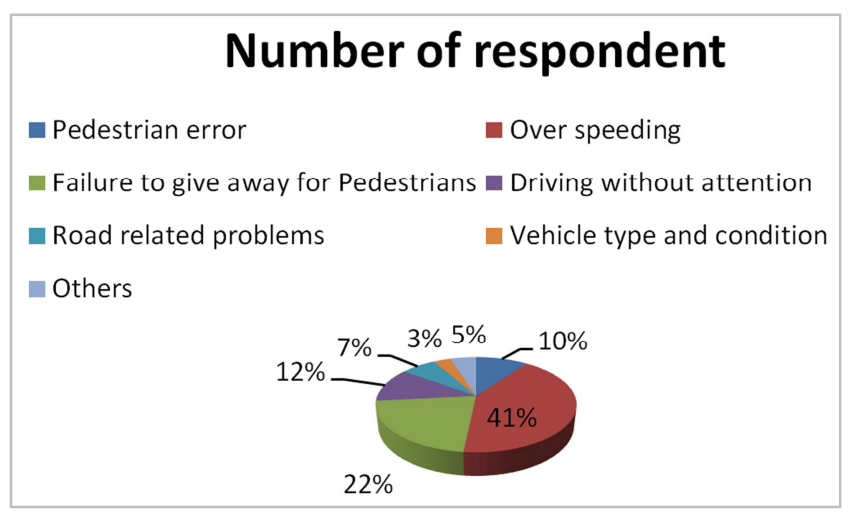

Figure 5. Variation of respondent on traffic accident.

As seen from the Figure 5 above, the major causes of road traffic safety problems obtained from pedestrians perspectives $41 \%$ due to over speed, $22 \%$ due to failure to give priority for pedestrians, $11.6 \%$ due to distractive driving, pedestrians error $10 \%$, road related problems $7 \%, 5 \%$ due to other factors and $3 \%$ due to vehicle related problems. 


\subsubsection{Traffic Safety Problems Obtained from Drivers Perspective's}

large and medium trucks.

The total numbers of samples of driver's respondent selected for this study was 50 drivers including motorcycle to

Table 7. Demography of Driver's Respondents on traffic safety problems.

\begin{tabular}{|c|c|c|c|c|}
\hline No & Drivers background & No, respond & & In percent $(\%)$ \\
\hline \multirow{4}{*}{1} & \multirow{4}{*}{ Age } & $<18$ & 7 & 14 \\
\hline & & $18-25$ & 21 & 42 \\
\hline & & $26-49$ & 20 & 40 \\
\hline & & $>50$ & 2 & 4 \\
\hline \multirow{3}{*}{2} & \multirow{3}{*}{ Education background (level) } & primary & 31 & 62 \\
\hline & & Complete 10 & 17 & 34 \\
\hline & & college & 2 & 4 \\
\hline \multirow{2}{*}{3} & \multirow{2}{*}{ Gender } & Male & 49 & 98 \\
\hline & & Female & 1 & 2 \\
\hline \multirow{2}{*}{4} & \multirow{2}{*}{ Awareness on traffic rules } & Aware & 42 & 84 \\
\hline & & Not aware & 8 & 16 \\
\hline \multirow{2}{*}{5} & \multirow{2}{*}{ Awareness on minimum distance to overtake } & Aware & 12 & 24 \\
\hline & & Not aware & 38 & 76 \\
\hline \multirow{2}{*}{6} & \multirow{2}{*}{ Awareness on parking } & Aware & 24 & 48 \\
\hline & & Not aware & 26 & 52 \\
\hline \multirow{2}{*}{7} & \multirow{2}{*}{ Awareness on road side furniture } & Aware & 44 & 88 \\
\hline & & Not aware & 6 & 12 \\
\hline \multirow{3}{*}{8} & & $30-40 \mathrm{KM}$ & 7 & 14 \\
\hline & Awareness on speed & $50-60 \mathrm{KM}$ & 31 & 62 \\
\hline & & $>80 \mathrm{KM}$ & 12 & 24 \\
\hline
\end{tabular}

From the total driver's respondent's drivers age $<18$ years are $7(14 \%)$, between 18-25 years are $21(42 \%)$, between $26-$ 49 are $20(40 \%)$ and $2(4 \%)$ drivers are above 50 years old.

Assessment made on the awareness of drivers on the use of traffic sign and traffic regulation $42(84 \%)$ are aware and 8 $(16 \%)$ of the respondents have no enough awareness on traffic rules. The other checked on awareness of the drivers is on driving speed limit. From all drivers including the motorcycles $31(62 \%)$ of the drivers drive between 50- 60 $\mathrm{km} / \mathrm{hr} .7(14 \%)$ of the drivers drive between $30-40 \mathrm{~km} / \mathrm{hrs}$. and $12(24 \%)$ respondents drive above $80 \mathrm{~km} / \mathrm{hrs}$.

The awareness of drivers on the minimum distance between two vehicles allowed to them and on minimum distance to overtake, majority of the drivers have no good awareness which means $38(76 \%)$ are not aware and $12(24 \%)$ of the drivers are aware. According to the driver's perspective's the major problems of traffic safety problems at study are speed, awareness of pedestrians on the traffic rules, Road side trade, inefficient skill of drivers, road condition and other factors which are $40,18,6,20,12$ and $4 \%$ respectively.

The other assessment make on drivers are whether they have good awareness on road sign furniture. From the respondent $32(64 \%)$ are fully aware and the left $18(36 \%)$ are partially aware.

\subsubsection{Causes of Traffic Safety Problems Obtained from Traffic Police Perspective's}

According to the traffic police report the main cause traffic accident in Shashemene town from 2014 to 2018 is not giving priority for pedestrians, following too closely, over speed, failure to give-way for other vehicle, Driving Without respecting Right-hand Rule and risky overtaking.

Generally, the causes of road traffic accident are grouped as human related problems and non-human related problems. (From those mentioned factors, driver's related error, passengers and pedestrian error are categorized as human related problems.

Table 8. Causes of Road Traffic Accident According to Traffic Police Perspectives.

\begin{tabular}{|c|c|c|c|c|c|c|}
\hline Causes of RTA & Fatal injuries & $\begin{array}{l}\text { Major } \\
\text { injuries }\end{array}$ & $\begin{array}{l}\text { Minor } \\
\text { injuries }\end{array}$ & $\begin{array}{l}\text { Property } \\
\text { damage }\end{array}$ & $\begin{array}{l}\text { Total of } \\
\text { accident }\end{array}$ & Percent \\
\hline Excessive speed & 17 & 3 & 11 & 23 & 54 & $18 \%$ \\
\hline Not giving priority for pedestrians & 15 & 6 & 10 & 15 & 46 & $15 \%$ \\
\hline Failure to give-way for other vehicle & 6 & 2 & 4 & 9 & 21 & $7 \%$ \\
\hline Risky overtaking & 9 & 4 & 5 & 15 & 33 & $11 \%$ \\
\hline Following too closely & 8 & 1 & 6 & 13 & 28 & $9 \%$ \\
\hline Not respecting traffic rule & 3 & 5 & 4 & 11 & 23 & $8 \%$ \\
\hline Pedestrian failure to respects traffic rule & 10 & 5 & 7 & 11 & 33 & $11 \%$ \\
\hline Due to vehicle failure & 4 & 1 & 3 & 5 & 13 & $4 \%$ \\
\hline Due to road problems & 2 & 0 & 1 & 4 & 7 & $2 \%$ \\
\hline Others & 1 & 3 & 5 & 4 & 13 & $4 \%$ \\
\hline unknown & 3 & 2 & 8 & 2 & 15 & $5 \%$ \\
\hline
\end{tabular}


This account $89 \%$ of total road traffic accident and those factors related non- human related problems (vehicle failure, road problems and others factors accounts $11 \%$ of total traffic accident happen during past five years. But this finding cannot conclude the above figure is the only causes of road traffic accident, it depends on the traffic police reports to identify the causes of accidents.

\subsubsection{Temporal Variation of RTA Occurrence at Shashemene Town (2014-2018)}

Based on time of the RTA occurrence, the maximum number of RTA occurrence were at night time which accounts $51 \%$ of total RTA and during day time the occurrence of RTA is $47 \%$ and $2 \%$ are undetermined.

From the duration of $2014-2018$, the maximum number of RTA occurred at time of day were in 2017 and minimum RTA during day time were in 2018. And also the maximum numbers of RTA during night time were in 2018 which accounts $57 \%$ and lowest value of RTA are recorded in 2017 which is $40 \%$.

The maximum number of RTA is occurred in 2014 and 2015 which covers about $48 \%$ of all accident registered at study areas.

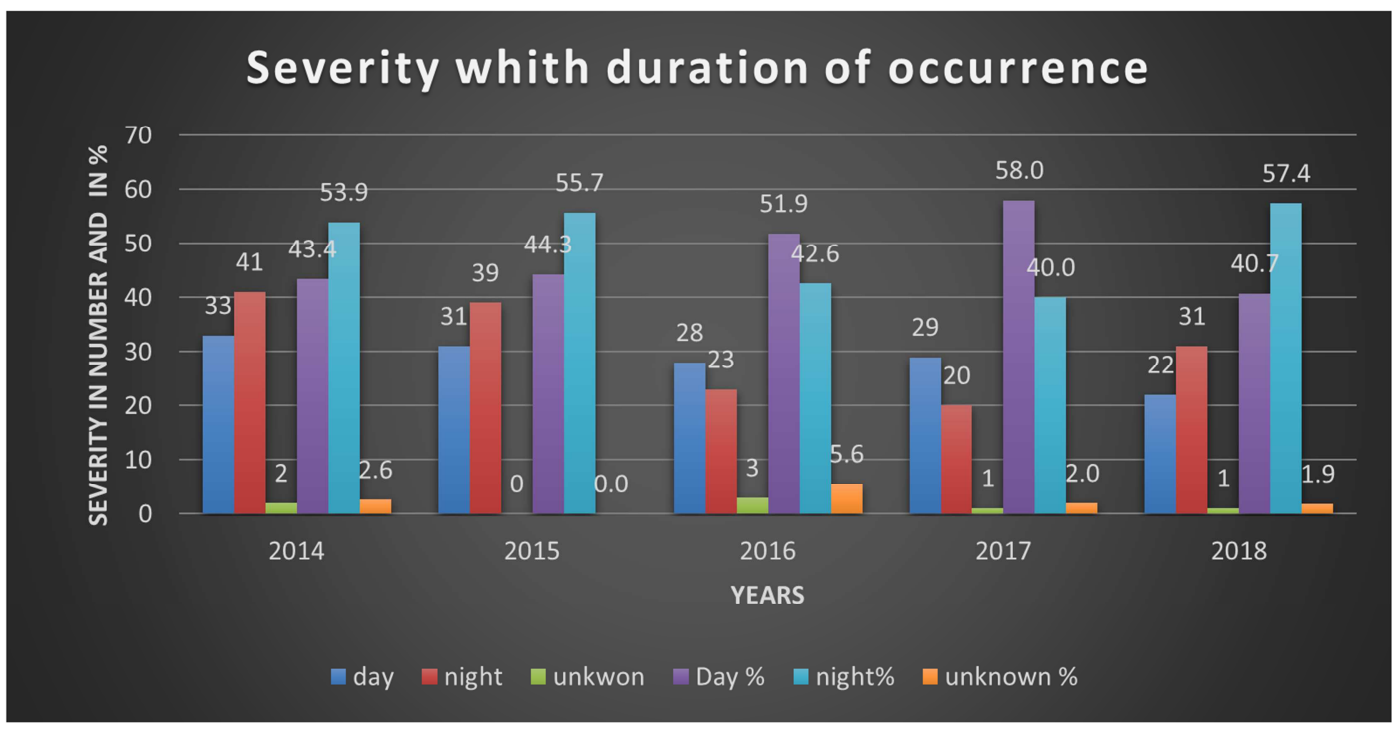

Figure 6. Distribution of traffic severity according to temporal variation of RTA occurrence.

\subsubsection{Distribution of RTA on Road Users}

The researcher tried to categorize the road users vulnerable to RTA, are categorized in to pedestrians, passengers, drivers, motorcyclist and cyclist and others. From those road users the vulnerability of pedestrians to accidents is high from other which covers $46.7 \%$, passenger $20.7 \%$, drivers $14.5 \%$. Motorcycle $6.9 \%$, cyclist and others covers $9.65 \%$.
As seen from the Figure 6. pedestrians and passenger is highly victim when compared to other which covers about $67 \%$ of total crashes that happen to road users.

Consequently, drivers, including motorcyclist and cyclist covers about $23 \%$ of total accident caused during $2014-2018$ at the study areas and the others road users like cart and animals covers $8 \%$ of the crashes.

Table 9. Distribution of RTA on road users.

\begin{tabular}{|c|c|c|c|c|c|c|c|}
\hline \multirow{2}{*}{ Road Users } & \multicolumn{5}{|l|}{ Year } & \multirow{2}{*}{ Total } & \multirow{2}{*}{ In \% } \\
\hline & 2014 & 2015 & 2016 & 2017 & 2018 & & \\
\hline Pedestrians & 38 & 40 & 19 & 24 & 21 & 142 & $46.7 \%$ \\
\hline Passenger & 18 & 7 & 17 & 6 & 15 & 63 & $20.7 \%$ \\
\hline Drivers & 9 & 11 & 8 & 10 & 6 & 44 & $14.5 \%$ \\
\hline Motorcyclist & 5 & 6 & 3 & 4 & 3 & 21 & $6.9 \%$ \\
\hline Cyclist & 2 & 1 & 0 & 2 & 0 & 5 & 1.655 \\
\hline Others & 4 & 5 & 7 & 2 & 9 & 25 & $8 \%$ \\
\hline
\end{tabular}

\subsubsection{Identified Black Spot Areas and Its Analysis}

Totally, about nine black spot locations are identified within the study areas. Table 10 shows that the calculated values of priority value based on fatalities and injuries for each black spot locations.

The highest priority value is recorded at kuyera broad (kersa) (153), kofele road in front of lead star and in Sole
River (106), Alaba road (71), tele (awassa exit) (52), Dadimos college (29), tekliye (34), 010 kebele (gomista) (30), in front of Dr. Urgessa (27), and Zerihun garage (23).

There are also others black spot areas which are identified and not written here due to the priority rules. Therefore if the value of p-value is less than 15 it is not classified as black spot areas (dangerous location).

As indicated on the table 10 based on the $p_{-}$values of the 
location their rank can be listed in the table 10 according to their $\mathrm{p}_{-}$values.

Table 10. Identified black spot areas at shashemene town (2014-2018).

\begin{tabular}{lllll}
\hline Black spot areas & Fatalities & Major injury & Minor injury & Priority values \\
\hline Kuyera road (kersa) & 21 & 10 & 18 & 153 \\
Kofele road & 15 & 5 & 16 & 106 \\
Tele (awassa exit) & 7 & 4 & 5 & 52 \\
Alaba road & 9 & 7 & 5 & 29 \\
Dadimos college & 5 & 1 & 1 & 34 \\
Tekliye (04kebele) & 4 & 2 & 8 & 30 \\
010 kebele & 3 & 3 & 6 & 27 \\
Dr. urgessa clinic & 4 & 2 & 1 & 23 \\
Zerihun garage & 2 & 3 & 4 & \\
\hline
\end{tabular}

Table 11. Identified and rank of black spot location in shashemene town (2014-2018).

\begin{tabular}{ll}
\hline Black spot location & Rank \\
\hline Kuyera road (kersa) & 1 \\
Kofele road & 2 \\
Alaba road & 3 \\
Tele (awassa exit) & 4 \\
Tekliye (04 kebele) & 5 \\
010 kebele (gomista) & 6 \\
In front of Dadimos college & 7 \\
In front of Dr. urgessa Clinic & 8 \\
Zerihun garage & 9 \\
\hline
\end{tabular}

\subsubsection{Causes of Road Traffic Accident at Black Spot Areas}

The causes of road traffic accident at study areas and identified black spot location are listed in the table12. It can be categorized as driver's error, pedestrian's error, and vehicle error and road condition.

Table 12. Causes of RTA at black spot areas.

\begin{tabular}{lll}
\hline Rank & Location & Causes of crashes \\
\hline 1 & Kuyera road (kersa) & Speed, slope, road geometry, narrowness of lane width and absence of side walk \\
2 & Kofele road & Speed, absence of speed breaker, slope, following too closely, unsafe lane change and distractive driving \\
3 & Alaba road & Absence of side walk, speed, night driving, neglecting warning sign post and distractive driving \\
4 & Tele (awassa exit) & Traffic congestion, slope, speed, road side parking and zebra crossing \\
5 & Tekliye (04kebele) & Speed, zebra crossing and neglecting warning posts \\
6 & 010 kebele (gomista) & Absence of side walk, narrow road width and speed \\
7 & Dadimos college & Absence of side walk, speed, wrong way driving congestion of road users \\
8 & In front of Dr. urgessa Clinic & Speed, zebra crossing, not giving priority for pedestrians and neglecting road side posts \\
9 & Zerihun garage & Road side parking, narrowness of carriageway, wrong way driving \\
\hline
\end{tabular}

The above mentioned black spot areas are identified by using site observation, using crash data and using safety audit checklist.

\subsubsection{Variation of RTA Frequency on Identified Black Spot Area}

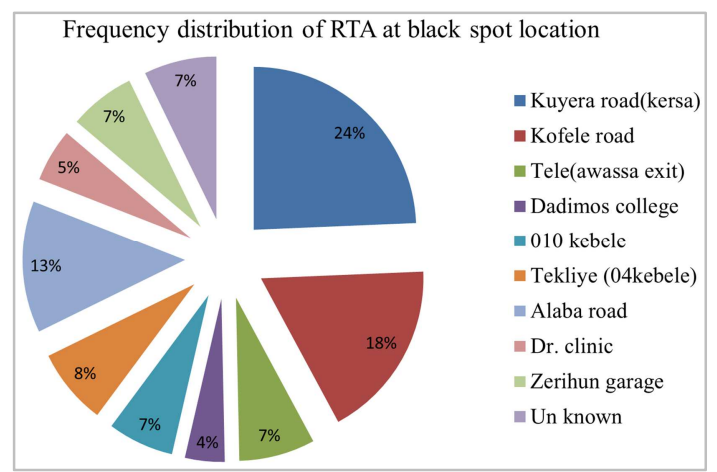

Figure 7. Distribution of road traffic accident at black spot location.
As observed from the above Figure 7 from total of the crashes happened at study area are: fatal injury $26.64 \%$, major injury $12.83 \%$, minor injury $21.71 \%$ and property damage of $38.82 \%$ which is high when compared to the other injuries.

From the severity type, seen from the Figure 7, fatal injury, major and major injury and also property damage is happening at Kuyera road especially at kersa high which covers $24 \%$ from all areas where crash recorded and the lowest number of accident are recorded around Dadimos College which covers about $4 \%$, on kofele road $18 \%, 13 \%$ on Alaba road, exit of Awassa road $7 \%$ and also tekliye, kebele 010 around gomista $7 \%$, around Dadimos College $4 \%$ and in front of dr. urgessa clinic 7\% and zerihun garage covers $5 \%$ from all the accident. Most of the traffic accident caused on this area is due to speed, not giving priority for pedestrians, lack of awareness on road traffic safety, due to poor law enforcement, due to driver's error (concerning skill and in attentiveness, driving after they take drug like chat and shisha) narrowness of the carriage way, absence of pedestrian's 
walkway and lack of road side furniture's.

\section{Conclusion and Recommendation}

\subsection{Conclusion}

In general road traffic accident is causing high impact on human life and economy in shashemene town, especially those areas selected as black spot area such as Kuyera road (kersa), kofele road, tele, 010kebele around gomista, 04kebele around tekliye, Alaba road and zerihun garage are some of the area that highly loses human life and misses a lot of money due to traffic accidents.

According to the finding of this study, the major contributing factor for road traffic accident at study area are, excessive speed, inefficiency of drivers skill, failures of not giving priority for pedestrians, drivers not respecting right hand rule, pedestrians not respecting traffic rules, drivers not respecting other road users, inadequate pedestrian awareness on traffic safety problems, due to poor road safety furniture, un availability of sufficient walkway, narrowness of lane, lack of speed limit and due to vehicle condition.

The studies also show that the number of traffic accident is reduced for three years 2016-2018 due to some measurements taken by local authority like setting rumble strips and speed breaker on some black spot area, giving awareness for road users especially for pedestrian through training at school and religious place and preparing billboard which shows traffic accident risk and how pedestrians use the road with collaboration of ERA, traffic police and transport office.

Lack of adequate and improper recording of traffic accident data like type of accident, severity class (fatal, major injury, minor injury and property damage), accident year, accident location, time of occurrence, type of vehicles involved, reasons or accident contributing factors, result of collision and many others by relevant authorities in the study area is the major problem to identify black spot area easily.

The study also identify that the problem of under reported traffic accident especially injured caused by motorcycle which is high. The problems behind not reporting the traffic accident was the interference of government politics into the reporting bodies, poor recording method of traffic accident, there is not good relation with those who do on the field and prepare report in the office and they have no computer data base management to record all the accident.

In addition, the traffic accident data in this research have no full information, such as location of crashes, identifying fault maker, drivers experience and the registered crashes are not fulfilling standard registration of crashes.

\subsection{Recommendation}

1. It is known that there is not standardized rule and method to mitigate the traffic accident. So it is better to do research to identify major causes and to create new intervention method.

2. Since the major vulnerable road user affected by traffic accident is pedestrians, it is highly advised to improve pedestrian safety by giving awareness through training at all sector, improving road infrastructure, speed limit, preparing the education on traffic rules at school as a course and law enforcement on traffic rules and regulations.

3. Creating a good relation with other regional institution like ERA, transportation agency and traffic police to improve road safety.

4. Inviting non-governmental organization to participate on road traffic safety.

5. Ethiopian road authority should give the power to local authority to install road side furniture and proper speed limit.

6. Road authority have to follow the road condition periodically and maintain properly to improve road safety.

7. Highly applying the law on speed, wearing seat belt and helmet, driving under influence of drug and children restraint.

8. Increasing the amount of penalty on those who violate the traffic rules.

9. Reforming the driving test to encourage driver's skill and controlling licensing system.

10. Reconstruct the improper road cross sectional element (increase lane width, shoulder, bridge, close improper median opening, traffic sign, sign inventory like speeds limit.

\section{References}

[1] W. H. O. Organization."Global Status Report On Road Safety" 2015, Geneva, Switzerland: World Health Organization (Who), 2015.

[2] Road Safety Risky Assessment. Syyed Adnan Raheel Shah, Nave Ahmed, Muhammad Aamir Bashir. 2018, Analysis Of Transport Policy And, Anagment For Low-, Middle And High Income Asia.

[3] "Understanding Passenger Influences On Driver Behaviour: Implications For Road Safety And Recommendations For Countermeasure Development,.,.". A. R. A. E. M. Michael. 2001, " Accident Research Centre, Monash University.

[4] Commission., Addis Ababa Police. Traffic Crashes Data Report. Addis Ababa, Ethiopia: S. N., 2015.

[5] Who. Global Status Report On Road Safety. Swizerland: World Health Organization, 2018.

[6] Redi, Kedir. Assessment Of Road Traffic Crash Data Collection And Managment System. Addia Ababa: S. N., 2015.

[7] Pedestrian Accidents And Road Safety Education In Sellected Deviloping Country. Sayer, I A And C J Palmer. P. Pa 3229/97.

[8] Effects Of Road Cross Sectional Elements On Road Traffic Crashes And Injury Severity At Middle Block In Addis Ababa. Mokonen, Alemu Daba. 2016. 
[9] Road Safety, No. 1,. Authority, Transport. 2014, Journal Of The Australasian College Of Transport And Traffic, Vol. Volume 25

[10] Transport, Ministry Of. National Road Safety Strategy. Soth Africa: Ministry Of Transport, 2016.

[11] Magnitude Of Road Traffic Accident Related Injuries And Fatalities In Ethiopia. Tefari Abegazi, Samson Gebremedin. 2018.

[12] Assessment Of Road Traffic Crash Data Collection And Management System Of Ethiopia. Redi, Kedir. Addis Ababa: S. N., 2015.

[13] Adminstration, Shashemene City. Shashemene Town Phisical And Socio Economic Profile. Shashemene: Shashemene City Adminstration, 2015-2016.

[14] Dan Gelinne, Unc Highway Safety. Road Safety Fundamentals, Concepts, Strategies And That Reduce Fatalities And Injuries On Road. Washington Dc: Federal Highway Office Of Safety, 2017.
[15] Adminstration, Shashemene City. Shashemene City Adminstration Physical And Socio Economic Profile. Shashemene: S. N., 2015.

[16] Assessment Of Road Taffic Crash Data Collection And Manegment Sytem Of Ethiopia. Redi, Kedir. 2015.

[17] Wichuda Kowtanapanich. Black Spot Identification, Methods In Thailand. Faculty Of Civil Engineering, Mahusarakam University: 126-34.

[18] K. Geertz, G. Wets. Black spot Analysis Method: Literature Review. Limburg University Centrum. Belgium: February 2003. Road Traffic Accident Fact Sheet. Belayneh, Abebe Bekele. 2015, Ethiopias Steps Survey.

[19] Sujin Munginimit, Kiettipang Jierranaitanakit, Songrit Chayanan. 4th Irtad Conference Road Safety Data: Collection and Analysis For Target Setting And Monitoring Performance And Progress, Data Analysis For Black Spot Identification. Seoul September, 2009. 